\title{
UMA POSSIBILIDADE DE PAISAGEM NA PRÁTICA DO IPHAN À LUZ DA EXPERIÊNCIA DE GUSTAVO GIOVANNONI
}

\author{
A LANDSCAPE POSSIBILITY IN THE IPHAN'S PRACTICE \\ IN THE LIGHT OF GUSTAVO GIOVANNONI'S EXPERIENCE
}

\author{
Hugo Stefano Monteiro Dantas \\ Pedro Augusto Queiroz de Souza \\ Mariana Silva Rossin \\ Thamires Augusto de Barros Chaves \\ Ana Rita Sá Carneiro
}

\begin{abstract}
RESUMO
O presente artigo discute as implicações e os desafios quanto à salvaguarda da paisagem nas políticas preservacionistas brasileiras, recorrendo às proposições teóricas de Gustavo Giovannoni no século XX como possível meio de reflexão sobre a atuação do Instituto do Patrimônio Histórico e Artístico Nacional - Iphan. Apesar de não fazer menção a palavra "paisagem", Giovannoni aproxima-se dela, a partir do conceito de "ambiente", no entanto, a paisagem está presente no decreto-lei que institui o principal instrumento de proteção do Iphan, o tombamento, e, ainda assim, se restringe a termos como "entorno", "vizinhança" e "visibilidade". Assim, para a construção da narrativa, são locados dois estudos de caso da atuação do Iphan, servindo de suporte e objetos para a reflexão proposta: o processo de tombamento do Entorno da Casa de Chico Mendes em Xapuri/AC e o processo de tombamento do Conjunto Histórico, Arquitetônico e Paisagístico de Cataguases/MG.
\end{abstract}

Palavras-chave: Paisagem. Gustavo Giovannoni. Iphan. Políticas de preservação.

\section{ABSTRACT}

This article discusses the implications and challenges regarding the safeguarding of the landscape in Brazilian preservationist policies, considering Gustavo Giovannoni's theoretical propositions in the 20th century as a possible way of reflection on the performance of the National Historical and Artistic Heritage Institute - Iphan. Despite not mentioning "landscape", Giovannoni approaches it based on the concept of "environment", however, the landscape is present in the decree-law that institutes the main protection instrument of Iphan, the "tombamento", and, even so, it is restricted to terms such as "surroundings", "neighborhood" and "visibility". Thus, for the construction of the narrative, two case studies of Iphan's performance are located, serving as support and objects for the proposed reflection: the process of "tombamento" the Surrounding of the House of Chico Mendes in Xapuri/AC and the process of "tombamento" the Historical, Architectural and Landscape Complex of Cataguases/MG.

Keywords: Landscape. Gustavo Giovannoni. Iphan. Preservation Policies. 


\section{INTRODUÇÃO}

Historicamente, a compreensão da paisagem tem sido uma tarefa complexa, com abordagens e perspectivas muito distintas que permeiam os mais diversos campos do saber. Desde as concepções puramente morfológicas, como as concebidas por Carl Sauer em 1925, até abordagens filosóficas da paisagem enquanto categoria do pensamento, como as cunhadas por George Simmel (1913), os estudos da paisagem vêm reafirmando as suas múltiplas possibilidades de apreensão ao longo do século XX e permanecem ainda no XXI.

Para Jean-Marc Besse (2014), a paisagem constitui uma nova perspectiva para o urbanismo na concepção das cidades, ocupando um lugar crucial nesse âmbito, associada a temas como a identidade dos lugares, ordenamento do espaço e a proteção dos meios naturais ${ }^{1}$. Na visão de Berque (1994), a paisagem não deve ser considerada apenas um "espelho da alma"; isso é, ela está relacionada a objetos concretos, que realmente existem à nossa volta, configurando assim algo mais do que apenas uma psicologia da percepção: "Em outras palavras, a paisagem não reside apenas no objeto, nem apenas no sujeito, mas na complexa interação entre os dois termos" (BERQUE, 1994, p. 5), em diversas relações de espaço e tempo. E é na própria complexidade dessa intersecção que o estudo da paisagem se concentra: "Em suma, a paisagem é uma entidade relacional e dinâmica, onde a natureza e a sociedade, a contemplação e o ambiente estão em constante interação" (BERQUE, 1994, p. 6). Nesse sentido, nas palavras de Courajoud (2011), a paisagem pode ser considerada como:

“[...] o lugar do relacional onde todos os locais só são compreensíveis por referência a um conjunto que se integra, por sua vez, num conjunto mais vasto. E o que faz com que não haja confusão ou dispersão dos dados sensíveis é, sem dúvida, o facto de que as coisas que a

1 Besse (2014) elenca cinco "entradas" para a paisagem, que podem ser articuladas entre si para viabilizar sua melhor compreensão: a paisagem enquanto representação cultural e social; a paisagem enquanto território fabricado e habitado; a paisagem enquanto ambiente material e vivo das sociedades humanas, a paisagem enquanto experiência fenomenológica e a paisagem como projeto. compõem não se ignoram e estão ligadas por um mesmo pacto" (COURAJOUD, 2011, p. 217).

Veras (2014, p. 24) afirma que essa forma de compreender a paisagem põe mais uma vez em evidência sua complexidade, ao passo que expressa "tempos sobrepostos, aparência da forma, dinâmica da natureza como suporte e cultura, produto da consciência do homem, numa relação contínua que expressa, no movimento, transformações e permanências".

Quando as noções de paisagem são aplicadas ao campo das políticas de preservação, sua polissemia comumente deixa margem para diferentes interpretações entre as partes envolvidas nos processos institucionais. Entre os teóricos e técnicos que buscaram contribuir com a salvaguarda da paisagem, a partir de políticas urbanísticas de viés preservacionista, se insere Gustavo Giovannoni, engenheiro italiano do início do século $X X$ que, de acordo com Andrea Pane (2013, p. 33-34), é considerado o "pai fundador" dos estudos da arquitetura italiana, tendo contribuído ainda para, ao menos, três campos disciplinares: a história da arquitetura, o restauro e o urbanismo.

No ideário nacional, a teoria e prática de Gustavo Giovannoni tem enfoque como contribuição para as questões da conservação urbana. Célebres livros como o de Françoise Choay "A alegoria do patrimônio" (1992) e "Gustavo Giovannoni: Textos escolhidos" (2013) organizado por Beatriz Kühl, introduziram o pensamento de Giovannoni, refletindo acerca das questões urbanísticas na obra do autor. Todavia, foi a partir das teses de Pedro Freitas (2012) e Renata Cabral (2013) que a teoria de ambiente de Giovannoni veio à tona na literatura brasileira. Tais autores procuram abordar de que forma a noção de "ambiente" contribui no sentido da salvaguarda da paisagem urbana em áreas históricas, viabilizada por alguns instrumentos como o "desbastamento edilício".

As dificuldades centrais na efetivação da salvaguarda da paisagem urbana, limitada pelos órgãos de proteção patrimonial, na maioria das vezes, como "ambiente" e "entorno", nos contextos italiano e brasileiro, permeiam caminhos semelhantes: a múltipla 
interpretação dos conceitos ligados à paisagem nas respectivas jurisprudências nacionais. Assim, o objetivo do presente artigo é discutir as implicações e os desafios quanto à salvaguarda da paisagem nas políticas preservacionistas brasileiras, recorrendo às proposições teóricas de Giovannoni no século XX como possível meio de reflexão sobre o tombamento, principal instrumento de proteção utilizado pelo Iphan. A discussão se desenvolve no contexto brasileiro em situações de entorno de edifícios tombados e de conjuntos urbanos históricos que não necessariamente incluem o termo paisagem urbana nos referidos processos de tombamento, mas nos quais é possível identificar essas intenções.

Optou-se pela escolha de situações representativas das práticas do Iphan na atualidade, mais especificamente após a promulgação da Chancela da Paisagem Cultural Brasileira, em 2009, no intuito de elucidar como as noções de "entorno" e "vizinhança" da coisa tombada continuam sendo protagonistas mesmo após a criação da chancela, pausada em $2013^{2}$. Dessa forma, foram elencados dois estudos de caso que abordam a atuação do Iphan, tornando possível uma maior aproximação com os princípios da prática de Giovannoni enquanto planejador urbano, servindo de suporte e objeto para a reflexão em questão: o Processo de Tombamento do Entorno da Casa de Chico Mendes em Xapuri/AC e o Processo de Tombamento do Conjunto Histórico, Arquitetônico e Paisagístico de Cataguases/MG. No primeiro, o tratamento do entorno suscita tanto rigor quanto o da própria edificação, que tem caráter "não excepcional", ou seja, só faz sentido enquanto elemento inserido no entorno. Já no segundo, foi localizada a operacionalização de um dos conceitos de Giovannoni aqui tratados: o desbastamento edilício dentro do perímetro tombado do conjunto urbano. No entanto, a priori da análise da experiência brasileira, iremos nos aprofundar na teoria do engenheiro italiano no tocante à paisagem urbana.

Zanirato $(2020$, p. 23) explica sobre as dificuldades de implementação e gestão da Chancela
da Paisagem Cultural "para se repensar a operacionalidade na gestão do território que
seria protegido como paisagem". A autora discorre, ainda, sobre as articulações mais recentes do Iphan para o redesenho de tal instrumento.

\section{Gustavo Giovannoni: entre ambiente E PAISAGEM}

Nesta primeira seção, procuraremos tensionar as noções presentes no ideário de Giovannoni com o conceito de paisagem, buscando no próprio Giovannoni, como também em estudiosos italianos e brasileiros, os subsídios para tal imbricação.

Dentre os estudiosos que buscaram entender a noção de "ambiente" de Giovannoni está Guido Zucconi (1999), ao discorrer que o uso de tal noção nas práticas italianas não foi, em si, uma colocação exclusiva do engenheiro. O termo já havia sido utilizado por teóricos que defendiam a beleza pitoresca das cidades, como é o exemplo de Camillo Sitte. Com base em diversos teóricos italianos, Cabral (2013) mostra que a Itália, no fim do século XIX, que até então era um país "onde se conservaram por muito tempo [...] não apenas os conjuntos urbanos antigos, mas também muitos dos costumes de vida pública" (SITTE, 1992, p. 25), estava passando por uma revolução industrial tardia, com experimentações de renovação e ampliação urbana ao gosto haussmaniano. Nesse contexto, "começa-se a falar de cidade, de identidade histórico-artística dos centros urbanos e do problema da sua tutela. Comparecem os primeiros artigos que desejam uma tutela séria daquilo que vem naquele momento definido como 'ambiente artístico'" (ZUCCONI, 1998 apud CABRAL, 2013, p. 48).

A partir do estudo feito por Zucconi (1999), em que há uma discussão entre a teoria e a prática de Giovannoni, fica evidente a preocupação do engenheiro com a conservação para além do monumento edificado de forma isolada, que deve ser preservado em seu contexto de existência enquanto obra de arte como parte de um todo harmônico, nos levando às noções do que viria a ser a salvaguarda da paisagem.

No entanto, não se tratava de uma ampliação simples e banal da escala, mas de uma mudança radical de abordagem dos problemas de conservação e proteção, não mais relacionada ao único monumento, era preciso olhar o monumento em seu contexto, em seu "ambiente" 
entendido não apenas como um local físico, mas como um conjunto de valores, morfologia, funções, usos, pessoas que o vivem (ARENA, 2013, p. 12, tradução nossa).

Por ser um engenheiro sanitarista especializado em história da arte, Giovannoni pôde unir suas bases teóricas - em que se destacam os conceitos tratados por Camillo Sitte e Charles Buls para o aspecto da beleza pitoresca das cidades antigas - com as questões higienistas da vida moderna. Rapalo (2017) afirma que na prática giovannoniana havia uma busca "por uma reconciliação entre as necessidades inelutáveis de higiene, trânsito e estética das cidades, em contraste com aqueles que acreditavam que as necessidades de saúde, mobilidade ou comércio eram mais técnicas que estéticas" (RAPALO, 2017, p. 237, tradução nossa).

Para Caravaggi (2002), Giovannoni foi o primeiro planejador urbano a "trazer de volta a paisagem, com todos os seus valores de tradição e memória, dentro de novos instrumentos de controle territorial: os planos municipais e os planos territoriais" (CARAVAGGI, 2002, p. 27, tradução nossa). A partir de Giovannoni:

A defesa da paisagem, portanto, frequentemente assume as características inovadoras de um projeto corajoso de recomposição entre passado e futuro, entre razões horizontais das identificações modernas e locais da memória, entre inovação e tradição. O pedido de uma certa nova codificação legislativa dos valores coletivos da paisagem [...] é acompanhado pelo pedido de novos instrumentos para alcançar concretamente a proteção do valor reconhecido (limitações aos direitos de propriedade, ferramentas para avaliação prévia de transformações elegíveis, etc.). A paisagem está organicamente ligada ao campo de ação do planejamento urbano (CARAVAGGI, 2002, p. 27, tradução nossa).

Conforme Zucconi (1999), para alcançar tais objetivos, a teoria de Giovannoni trabalha em conceitos implícitos na disposição legislativa, que lutam para assumir credibilidade legal e consistência operacional para o termo. Por sua vez, Cabral (2013) aponta que a noção de ambiente na operacionalização do termo na legis-

lação italiana, em princípio, era associada às questões de luz e perspectiva. Para Giovannoni, esses conceitos eram de extrema importância uma vez que, "o ambiente, o espaço e a luz são tão bons quanto, e às vezes mais do que, o design da arquitetura ou a decoração" (GIOVANNONI, 1999, p. 112, tradução nossa).

O monumento deveria, assim, "ser apreciado sem obstruções na linha de visada entre o observador (o público) e ele, não devendo, assim, ser privado de luz, assim como as obras de arte no interior deste monumento" (CABRAL, 2013, p. 52). A noção de ambiente, já em 1925, passaria a englobar também a noção de unidade e continuidade, quando Giovannoni sublinha o "elo harmonioso entre a obra e sua estrutura natural ou construtiva" (ZUCCONI, 1999, p. 129). Assim, o ambiente passa a ser entendido como:

“[...] elemento extrínseco da composição arquitetônica. Uma obra de arte, e especialmente uma obra arquitetônica, não vive orgulhosamente isolada, mas fica na rua em uma série contínua com outras obras das quais recebe reflexões e limitações de medidas, cores, ornamentos" (GIOVANNONI, 1925 apud ZUCCONI, 1999, p. 129, tradução nossa).

É interessante notar que, mesmo sem nunca ter se utilizado do conceito de paisagem, a teoria de "ambiente" de Giovannoni está alinhada às suas noções. Procuramos elucidar, ainda, que o primeiro estudo de que se tem conhecimento a abordar a filosofia da paisagem é referente ao trabalho de Georg Simmel, publicado em 19133. Dessa forma, é plausível a hipótese de que as noções de paisagem como a conhecemos hoje ainda não estivessem tão difundidas no início do século $X X$ na intensidade que ocorre na atualidade em diversas áreas do saber, como também o fato de Giovannoni se utilizar de termos mais próximos a sua experiência profissional enquanto planejador urbano. De toda forma, é possível perceber como a sua teoria converge em direção à definição de paisagem de teóricos da atualidade como Berque (1994), Besse (2014), e Courajoud (2011), que buscam compreendê-la enquanto uma totalidade dinâmica e evolutiva, a partir 3 Ver Simmel (2009). 
da intrínseca relação entre sujeito e objeto, passado e futuro, construído e não construído, não se limitando à visão morfológica referente exclusivamente aos elementos naturais e humanos que a constituem.

Giovannoni utiliza de instrumentos para a operacionalização da sua teoria, entre eles destacamos o diradamento edilizio ${ }^{4}$ (desbastamento edilício), que é definido pelo engenheiro italiano a partir de tais noções:

Assim a devastação poderia ser evitada. E se razões de higiene propusessem ao mesmo tempo trazer ar e luz a alguns pontos muito restritos das velhas ruas, bem se poderia dispersar as casas, retirando (diradando) alguns edifícios isolados sem importância e colocando em seu lugar pequenas praças ou pequenos jardins; abrir alguns pontos, sem se deixar seduzir pela regularidade geométrica de uma rua larga, sem transformar com novas construções o ambiente. Nem se diga que este ambiente é sujo; se é sujo em alguns lugares, não o é porque é antigo, e pode-se saná-lo sem precisar da extrema medicina da picareta (GIOVANNONI, 1908 apud FREITAS, 2013, p. 74).

Um caso que chama atenção é o da Piazza Garibaldi, na cidade italiana de Perúgia. Localizada próximo ao edifício da prefeitura e tribunais que estavam incluídos entre os edifícios monumentais da cidade, recebeu a proposta, no ano de 1916, de construção de um novo edifício em seu entorno; ficou a cargo do Conselho Superior de Antiguidades e Belas-Artes a avaliação e elaboração de um parecer a respeito do projeto. Dentre os encarregados dessa missão estava Giovannoni, sendo um dos responsáveis pela elaboração do parecer técnico, no qual foi relatada a inapropriada modificação do ambiente. A respeito disso, Cabral (2013, p. 58)

4 Em uma contextualização sobre a origem da palavra diradamento e para melhor entendimento da teoria de Giovannoni, Freitas $(2013$, p. 74$)$ relaciona a sua utilização ao termo "diradare", utilizado no cenário agrícola italiano que "remete à prática do cultivo em que plantas nocivas ou pouco desenvolvidas são retiradas para o fortalecimento da plantação como um todo"; sendo essa, uma metáfora para a retirada de unidades "que prejudicam a leitura ambiental numa análise filológica da estrutura urbana, rechaçando-se a associação comum e uniformizadora entre degradação, insalubridade e antiguidade" . expõe a desaprovação dos pareceristas para com a construção do novo edifício, classificando-o como arquitetura moderna e de altura exagerada, o que levaria a um desequilíbrio do ambiente, causando uma alteração da ordem da "calma e sobriedade de efeitos".

O parecer, datado de 1917, mostra o valor atribuído por Giovannoni à percepção do ambiente da Piazza Garibaldi, sendo possível observar a importância dessa percepção em um documento técnico, além do sentimento e das sensações que o meio urbano (ou, poderíamos dizer, a paisagem urbana) causaria em seus espectadores. A presença do conceito da "percepção" em trabalhos de Giovannoni anteriores ao parecer de Perugia é enfatizada por Cabral (2013), revelando uma aproximação antiga do engenheiro com o modo que o ambiente seria apreendido. Nesse sentido, o engenheiro considera que "a arquitetura não pertence apenas a quem produz ou quem a paga, mas também à cidade da qual vem fazer parte e vem refletir, sobre seus elementos, o sentimento que emana das suas linhas" (CABRAL, 2013, p. 76).

$\mathrm{Na}$ intenção de se aproximar da realidade, segundo Cabral (2013), Giovannoni também realiza estudos experimentais, utilizando fotografia e desenhos em perspectiva para a visualização de um "cenário futuro", tratando-se dos pedidos de novas construções e/ou reformas, para que fosse possível analisar o seu impacto no ambiente urbano. Como pode ser visto, tanto na sua atuação prática em processos de intervenção em áreas históricas, quanto na função de parecerista, o engenheiro é sensível ao tratar a cidade como "ambiente", "perspectiva", "unidade" e "panorama", aproximando-se assim da noção de paisagem. Supõe-se que isso tenha sido parte de seu processo de apropriação e compreensão diante da complexidade da paisagem.

$\mathrm{Na}$ verdade, a falta de uma precisão conceitual para a "paisagem" causou, na experiência italiana, disputas judiciais, as quais buscavam entender os limites dos termos utilizados pelo engenheiro - como defini-los, definir seus alcances, entre outras questões - em seus pareceres oficiais, como propõe Cabral (2013). Essa questão também pode ser observada no Brasil, quando o Iphan se utiliza de termos como "visibilidade" e "entorno" ao 
tratar da paisagem em seus processos de tombamento, ocultando o objeto propriamente dito ainda não devidamente apropriado, embora explicitado no Decreto-Lei $n^{\circ} 25$, de 1937. Termos esses que, abertos à compreensão e interpretação de terceiros, também centraram disputas de jurisprudência, como posto por Sant'Anna (1995).

Buscaremos, assim, discutir as inflexões presentes nas políticas preservacionistas no âmbito nacional, segundo os conceitos e direcionamentos praticados pelo Iphan, considerando a noção de paisagem adotada e os preceitos da teoria de Giovannoni para, em seguida, fazer o rebatimento nos estudos de caso selecionados.

\section{UMA FOBIA À NOÇÃO DE PAISAGEM: O IPHAN E A SALVAGUARDA DE ENTORNOS E CONJUNTOS URBANOS, A PARTIR DE NOÇÕES COMO "VISIBILIDADE" E "VIZINHANÇA"}

$\mathrm{Na}$ realidade brasileira, quando se trata de uma paisagem construída, sobretudo nas áreas de interesse histórico e cultural, o Decreto-Lei $n^{\circ} 25$, de 1937 é, ainda hoje, o documento legal que organiza a proteção do patrimônio histórico e artístico nacional por meio do Iphan. Como o próprio redator do decreto-lei - Rodrigo Melo Franco de Andrade - afirma, o texto foi baseado em diversos projetos apresentados anteriormente à criação do órgão. O autor cita o anteprojeto de Mário de Andrade, de 1936, o anteprojeto de 1925 de Jair Lins e, o Projeto de Lei $n^{\circ} 230$, de 1930, de Wanderley Pinho, assim "como a legislação estrangeira, sobretudo a francesa e mexicana" (ANDRADE, 1952 in ANDRADE, 2012, p. 108).

Cabral (2019) nos mostra que é no projeto de lei de Wanderley Pinho que se encontra uma maior proximidade com o que havia sido anteriormente discutido na legislação italiana. Pinho (1930) assim escreveu em seu anteprojeto:

Se isso julgarem conveniente à conservação, à luz, perspectiva e moldura de um imóvel catalogado, po- derão a Inspetoria, as repartições congêneres, os poderes estaduais ou municipais, desapropriar os imóveis, jardins, e terrenos da vizinhança de um imóvel catalogado (PINHO, 1930 apud CABRAL, 2019, p. 11, grifo nosso).

Cabral (2019) questiona ainda se a inserção da palavra "moldura", que não estaria presente na legislação italiana, seria uma forma de evitar as disputas que ocorreram na Itália devido às múltiplas interpretações da palavra "perspectiva". Por sua vez, Sant'Anna (1995) argumenta que a principal intenção da proteção da ambiência para Pinho estaria na garantia do desimpedimento da perspectiva visual do bem foco da preservação. De toda forma, mesmo tendo sido uma das bases para a redação final do Decreto-Lei $n^{\circ} 25 / 37$, a palavra "moldura" não foi inserida no documento final. No artigo 18 do decreto em questão utilizou-se o termo "visibilidade". No entanto, de acordo com Cabral (2019), Wanderley Pinho se aproxima das ideias de Giovannoni ao defender a preservação da cidade existente como um todo, não apenas os monumentos isolados e a construção dos novos centros próximos ao recorte preservado, conforme relato abaixo:

"[...] a nossa cidade tem como um valor grande esse cunho seu característico, que são os aspectos coloniais de algumas de suas ruas e construções. Toda a orientação de reforma, pois, deveria tomar como diretriz a conservação e resguardo dessas ruas estreitas, tortuosas, inclinadas, mas cheias de casas e palácios de antanho, repletos de arte velha e de tradições antigas. [...] Respeitemos, pois, essa velharia que não poderíamos remodelar sem feiura e que só poderemos embelezar destruindo, para levantar sobre as ruínas cousa totalmente nova. Repartamos a cidade velha urbs intangível e a cidade mais nova, sujeita às transformações constantes, [...] ofereçamos, assim, ao visitante e às gerações por vir um museu de antiguidade como um orgulhoso pergaminho de nossa prosápia, no bairro da Sé, e, como um atestado de nossa cultura contemporânea, a nova cidade. Elevemo-nos com esse estalão de alto valor moral na estética do apro- 
veitar a natureza e no respeito à arte e às lembranças do passado" (PINHO, 1925 apud CABRAL, 2019, p. 21).

Conforme Cabral (2019), a hipótese de que os termos "sítios" e "paisagens", tanto naturais como agenciados pela ação humana, foram inseridos no Decreto-Lei $n^{\circ} 25$ de 1937 para dar conta da dimensão urbana para além do monumento isolado, prevista por Pinho (1930) em seu projeto de lei. Entretanto, autoras como Sant'Anna (1995), Motta e Thompson (2010) mostram que a operacionalização dos termos em vigência no decreto-lei, em especial os termos "vizinhança" e "visibilidade", causaram recorrentes disputas judiciais na realidade brasileira. Para Sant'Anna (1995, p. 94) "além da discussão quanto aos limites físicos da vizinhança, o centro do problema tem sido a possibilidade de interpretação do conceito de visibilidade em termos óticos ou ambientais." Dessa forma, podemos perceber que a escolha de outros termos para além da paisagem suscitaram discussões semelhantes ao caso italiano; assim como "ambiente", a questão da "vizinhança" e da "visibilidade" levantam as mesmas indagações acerca dos limites da sua aplicação no objeto a ser tombado. Sobre o conceito de "visibilidade", Sant'Anna (1995) discorre que as disputas judiciais travadas acerca do termo focaram na sua interpretação, que estava sendo entendida tanto pela questão ótica, quanto da ambiência do bem.

No percorrer dos anos, o conceito de visibilidade "se consolidou enquanto visibilidade estética ou artística [...], entretanto, apesar da jurisprudência, a questão nunca se tornou pacífica e algumas ações foram perdidas em função da interpretação ótica do conceito legal de visibilidade" (SANT'ANNA, 1995, p. 101). A autora afirma ainda que, de modo geral, à interpretação do artigo 18, prevalece o que é expresso por Hely Lopes Meirelles:

O conceito de visibilidade para fins da Lei de Tombamento é amplo, alcançando não só a tirada da vista da coisa tombada, como a modificação do ambiente ou da paisagem adjacente, a diferença de estilos arquitetônicos, e tudo o mais que contraste ou afronte a harmonia do conjunto, tirando o valor histórico ou a beleza original da obra protegida (MEIRELLES, 1977 apud SANT'ANNA 1995 , p. 102 - grifo nosso)

Podemos perceber, mais uma vez, as imbricações entre o conceito de "ambiente" da teoria giovannoniana e as questões em âmbito nacional. A visibilidade, assim como o ambiente, evocaria a noção de um conjunto, ou ainda, nas palavras de Meirelles, uma paisagem adjacente. Tais questões podem também ser suscitadas a partir da leitura do processo de tombamento $n^{\circ} 1549-T-07$, referente à Casa de Chico Mendes e seu acervo, Xapuri-AC (ver Fig. 1). Já no pedido de tombamento, da Fundação Chico Mendes e do Comitê Chico Mendes, datado de 18 de agosto de 2006, pode ser elucidada a importância do entorno para o pedido, em que se lê que o bem teria o "risco de ter seu entorno irreversivelmente modificado caso não haja um instrumento legal que garanta tanto a proteção, da casa, quanto a proteção do seu entorno imediato" (IPHAN. Processo de tombamento $\mathrm{n}^{\circ} 1549-\mathrm{T}$ - 07, Casa de Chico Mendes e seu acervo, Xapuri-AC).

Em 1925, Giovannoni discute que um bem imóvel ou, ainda, um monumento de arte, não pode existir isolado. Em suas palavras, "grupos de pequenas casas, muros, torres, fontes, que apenas nessas condições do ambiente têm valor e significado, ou histórico, ou arquitetônico, ou pictórico: por vezes, é possível dizer que o monumento seja todo o conjunto" (GIOVANNONI, 2013a, p. 146). Esse parece ser o caso da Casa de Chico Mendes que, em verdade, seria um imóvel emblemático, para a Conselheira do Iphan, Jurema Machado, exatamente por ser "não excepcional. É uma casa com uma tipologia construtiva de repetição, e me pareceu, inclusive, idêntica à casa do lado. Então, julgo que o tratamento do entorno, independente da sua delimitação, merecia um rigor tão grande quanto o da própria casa" (IPHAN. Processo de tombamento $\mathrm{N}^{\circ} 1549-\mathrm{T}-07$, Casa de Chico Mendes e seu acervo, Xapuri-AC). Ainda, de acordo com Machado, o entorno, que seria um problema recorrente para o Iphan no caso da Casa Chico Mendes, teria, sim, um valor excepcional.

Devido à problemática levantada durante a $56^{\mathrm{a}}$ Reunião do Conselho Consultivo do Iphan e anos após o tombamento do bem, em 2013, o processo é reaberto para a normatização do entorno 


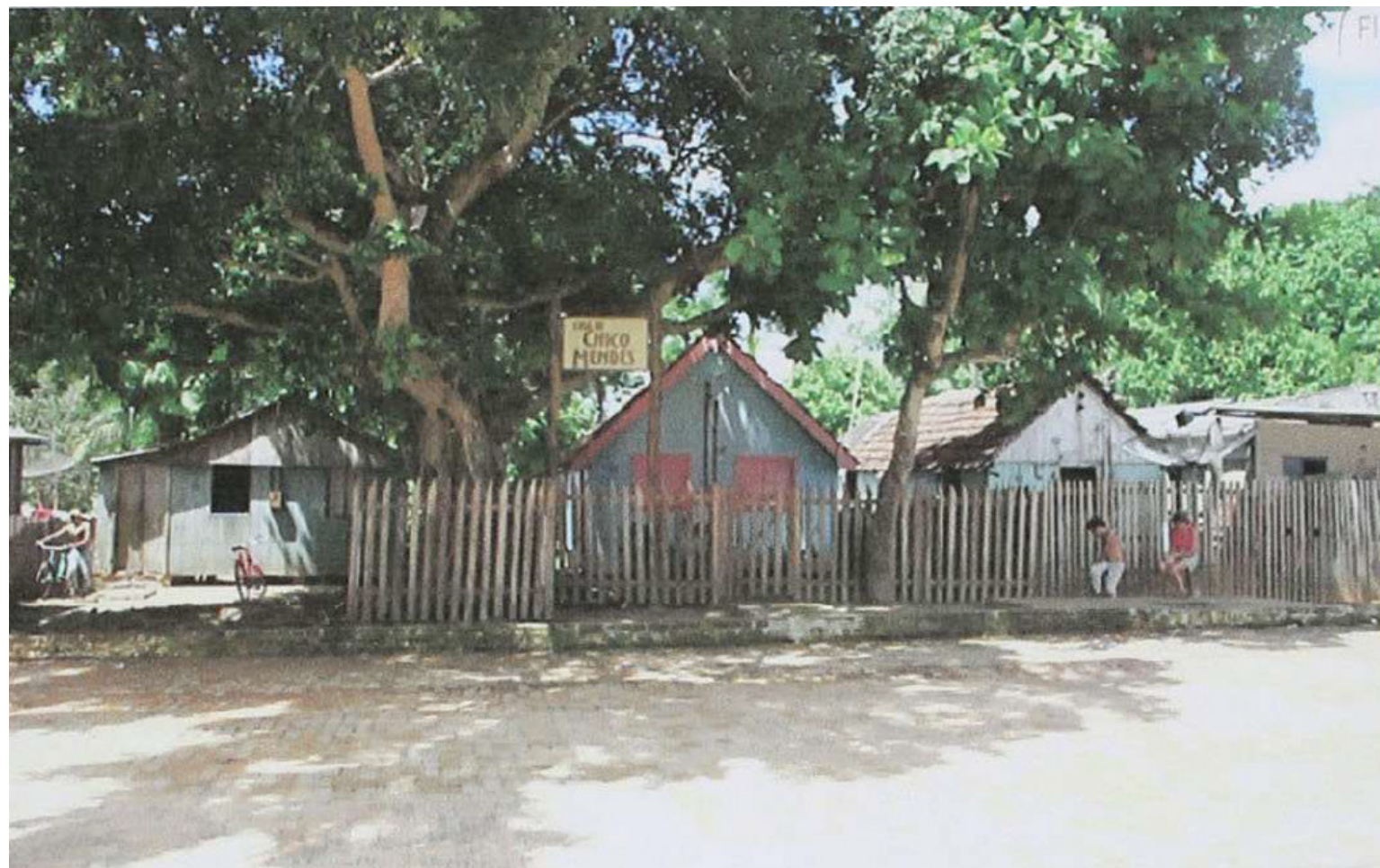

Figura 1: Casa de Chico Mendes ao centro e as casas que compõem o seu entorno imediato. Fonte: IPHAN. Processo de tombamento $\mathrm{n}^{\circ} 1549-\mathrm{T}-$ 07.

da Casa de Chico Mendes. Nas diretrizes de tal processo, como veremos a seguir, são elencados termos como "visibilidade" e "qualidade ambiental e paisagística". O que fortalece nossa hipótese de que, para o Iphan, tais termos, assim como a própria noção de entorno, seriam estreitas aproximações à noção de paisagem. Lê-se no Art. $3^{\circ}$ da portaria em questão:

I - Garantir a visibilidade da Casa de Chico Mendes em função do deslocamento a pé e nessa escala humana; II - Garantir a qualidade ambiental e paisagística que configura a ambiência da área de entorno em função da Casa de Chico Mendes pela presença expressiva da massa verde e da ocupação permeável e fluida das edificações contidas neste perímetro que remete ao ambiente rururbano à época de vida e assassinato do líder seringueiro em que a Casa se situava (IPHAN. Processo de tombamento $\mathrm{n}^{\circ} 1549-\mathrm{T}-07$, Casa de Chico Mendes e seu acervo, Xapuri-AC - grifos nossos).

Podemos perceber, também, como essa normativa se assemeIha com a teoria de Giovannoni até aqui apresentada. Garantir a qualidade ambiental e paisagística do entorno do bem pode ser entendida como sinônimo de uma salvaguarda que respeite as configurações históricas daquela paisagem. Nas palavras anteriormente apresentadas por Caravaggi (2002), a normativa buscaria um projeto corajoso de composição entre o futuro e o passado.

As questões de visibilidade e de qualidade ambiental e paisagística são resolvidas a partir da criação de diferentes setores do entorno da Casa de Chico Mendes. O entorno imediato da casa é demarcado como Setor de Proteção do Ambiente Construído I (SPAC I), enquanto que, o entorno adjacente seria o Setor de 
Proteção do Ambiente Construído II (SPAC II). Em termos gerais, o SPAC I representaria uma permanência tipológica do entorno, em que as edificações deverão permanecer com gabarito máximo de 1 pavimento térreo, sem ultrapassar a altura da cumeeira da Casa de Chico Mendes, tendo, ainda, os mesmos recuos preservados (ver Fig. 2).

Assim como acontece na teoria de Giovannoni, essas diretrizes buscam manter o equilíbrio de espaço, luz e da permanência da paisagem do conjunto. As demandas são ligeiramente flexibilizadas no SPAC II, onde as construções podem possuir até 5 metros de altura, um pouco mais do que a Casa de Chico Mendes. Enquanto flexibilizado, busca-se ainda não comprometer a paisagem ou, nos termos do artigo, a visibilidade do bem edificado. A preocupação com a composição do entorno, podendo ser lido como a paisagem na qual a edificação se insere, fica evidente com as proposições para os Setores de Espaços Públicos Livres Viários (SEPLV) e os Setores de Proteção do Ambiente Natural (SPAN). No primeiro, até mesmo o tipo de pavimentação é determinado, enquanto no SPAN, as espécies arborescentes devem ser mantidas ou trocadas por espécies idênticas. Assim, todos os
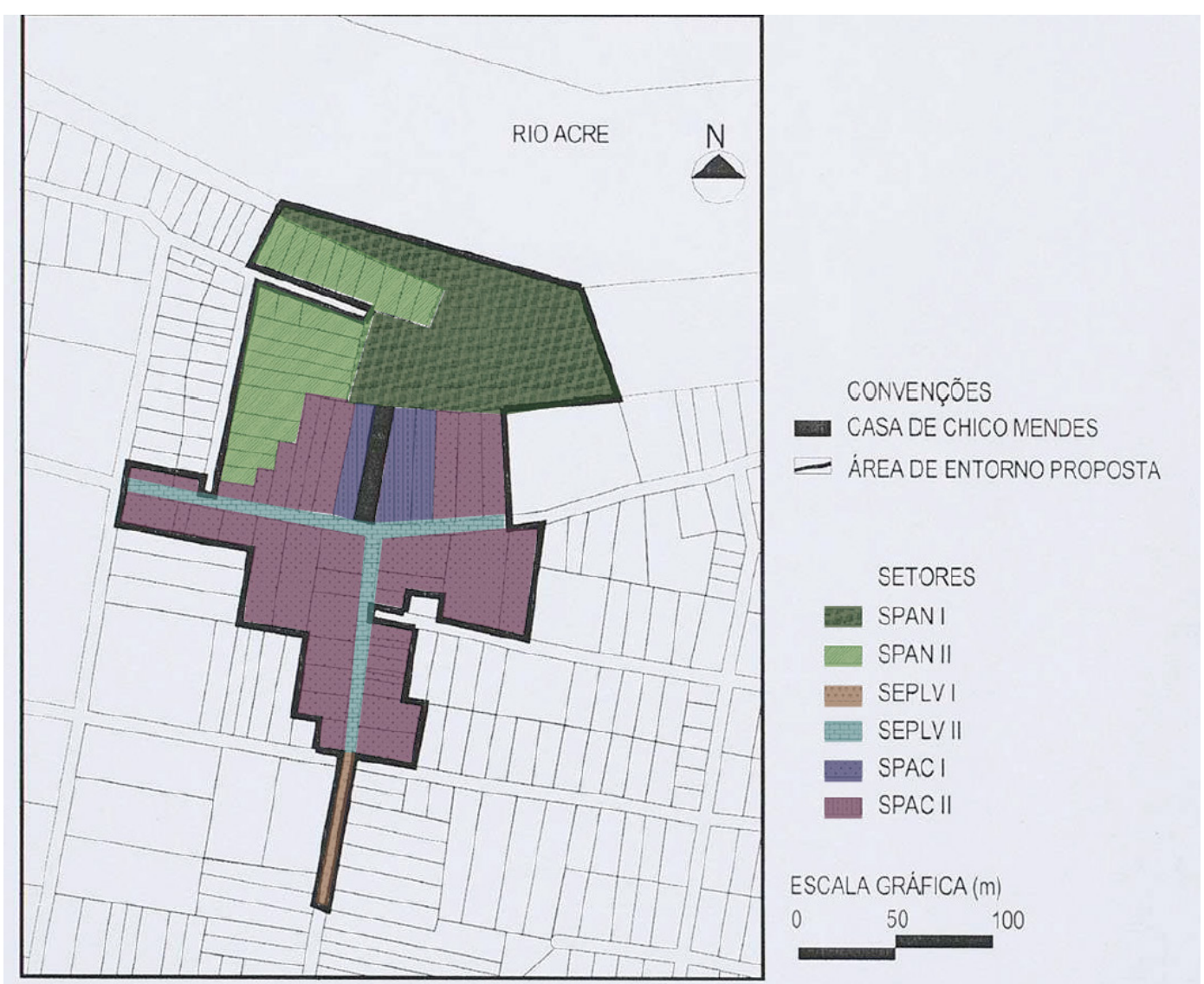

Figura 2: Mapa dos setores do entorno da Casa de Chico Mendes. Fonte: IPHAN. Processo de tombamento $n^{\circ} 1549-\mathrm{T}-07$ editado pelos autores) 
elementos passíveis de proteção do entorno-paisagem são protegidos.

Embora possamos encontrar diferentes pontos de convergência entre a teoria giovanniana e o caso da Casa de Chico Mendes, é a partir do processo de tombamento do Conjunto Histórico, Arquitetônico e Paisagístico de Cataguases-MG (ver Fig. 3) que podemos identificar, na prática do Iphan, uma rara e isolada aplicação de um instrumento cunhado por Giovannoni com foco preservação da paisagem: o desbastamento edilício.

A inscrição do conjunto nos Livros do Tombo Arqueológico Etnográfico e Paisagístico; Histórico e de Belas Artes aconteceu em $17 / 02 / 2003^{5}$, sendo objeto para a preservação das "vizinhanças dos bens tombados individualmente, sobretudo quanto à integridade física e visibilidade dos referidos bens", em que a altura máxima permitida para a construção seria de até três pavimentos, para não "desfigurar a escala urbana existente" (IPHAN, Processo de Tombamento ${ }^{\circ} 1342-T-94$, Conjunto Histórico, Arquitetônico e Paisagístico de Cataguases-MG). Pode-se notar, assim, que não há menção à paisagem no documento, atendo-se o parecerista a utilizar termos como "vizinhança" e "escala urbana".

Nesse caso, a legislação federal não foi incorporada à legislação em nível municipal preexistente. A Lei de Uso e Ocupação do Solo da cidade, de 1995, permite a construção, no perímetro tombado, de novos imóveis com até sete pavimentos, o que favoreceu a verticalização da área central da cidade.

Em março de 2011, a Prefeitura Municipal aprovou um projeto que seria construído à Rua Alferes Henrique de Azevedo, 124, dentro do perímetro tombado pelo Iphan, o qual seria composto por três blocos erguidos sobre pilotis e mais três pavimentos-tipo. A obra teve início alguns meses após, quando o alvará $n^{\circ} 4022$ de 2011 foi dado pelo município, apesar de o tempo máximo de retorno do Iphan sobre a autorização da obra ter se excedido. As edificações, de quatro pavimentos, que somavam doze metros de altura cada, embora estivessem dentro dos parâmetros

5 O processo de Tombamento Federal do Conjunto Histórico, Arquitetônico e Paisagístico de Cataguases foi aberto em 1994. construtivos permitidos pela legislação urbana municipal vigente (Leis Municipais $n^{\circ}$ 2.428/1995 e $n^{\circ} 3.135 / 2002$ - Código de Obras; $n^{\circ} 2.427 / 1997$ e $n^{\circ}$ 2.989/2001 - Uso e Ocupação do Solo e $n^{\circ} 3.546 / 2006$ - Plano Diretor), excediam o limite definido no processo de tombamento federal.

Assim, em julho de 2012, o Iphan, por meio de uma notificação extrajudicial, autuou o responsável pela obra, com base no artigo 17 do Decreto-Lei ${ }^{\circ} 25$, de 1937, o qual diz que "as coisas tombadas não poderão, em caso nenhum, ser destruídas, demolidas ou mutiladas, nem sem prévia autorização especial do Iphan, ser reparadas, pintadas ou restauradas, sob pena de multa de cinquenta por cento do dano causado" (BRASIL, 1937, p. 4). Na autuação, o órgão ainda determinou a imediata paralisação da obra, a demolição do quarto pavimento que estava sendo erguido em um dos blocos e a apresentação de um projeto adequando o que estava sendo erguido para atender as diretrizes que o tombamento federal previa (IPHAN, 2012). Apesar da tentativa de impugnação feita pelo proprietário da obra, em que afirmava que o município não possuía um plano de preservação com diretrizes específicas para tal, que o projeto cumpriu todas as obrigações legais e que já havia na cidade diversos outros imóveis com quatro e até mais pavimentos, inclusive dentro do perímetro de tombamento federal $^{6}$, não houve êxito e o processo seguiu. Ainda como tentativa de reverter a demolição do pavimento construído, a construtora Entre-Rios, proprietária da obra, contratou o arquiteto Cláudio Bahia para elaborar um parecer técnico sobre a situação.

Sobre a paisagem do conjunto, juntamente com a interferência da construção dentro do perímetro tombado, o parecerista recorreu ao "[...] olhar sobre a identificação e a preservação das características culturais do lugar e uma ação intencionalizada e instrumentalizada pelos preceitos supracitados das Cartas Patrimoniais selecionadas, pela Portaria 127/2009 IPHAN e pela Teoria de Cesare Brandi" (BAHIA, 2013, p. 17). Realizou assim, uma análise observando tal paisagem de diferentes pontos, tratadas por ele de "ambiência urbana e ambiência local".

6 Entrevista concedida pelo proprietário da Construtora Entre-Rios aos autores, em janeiro de 2020. 


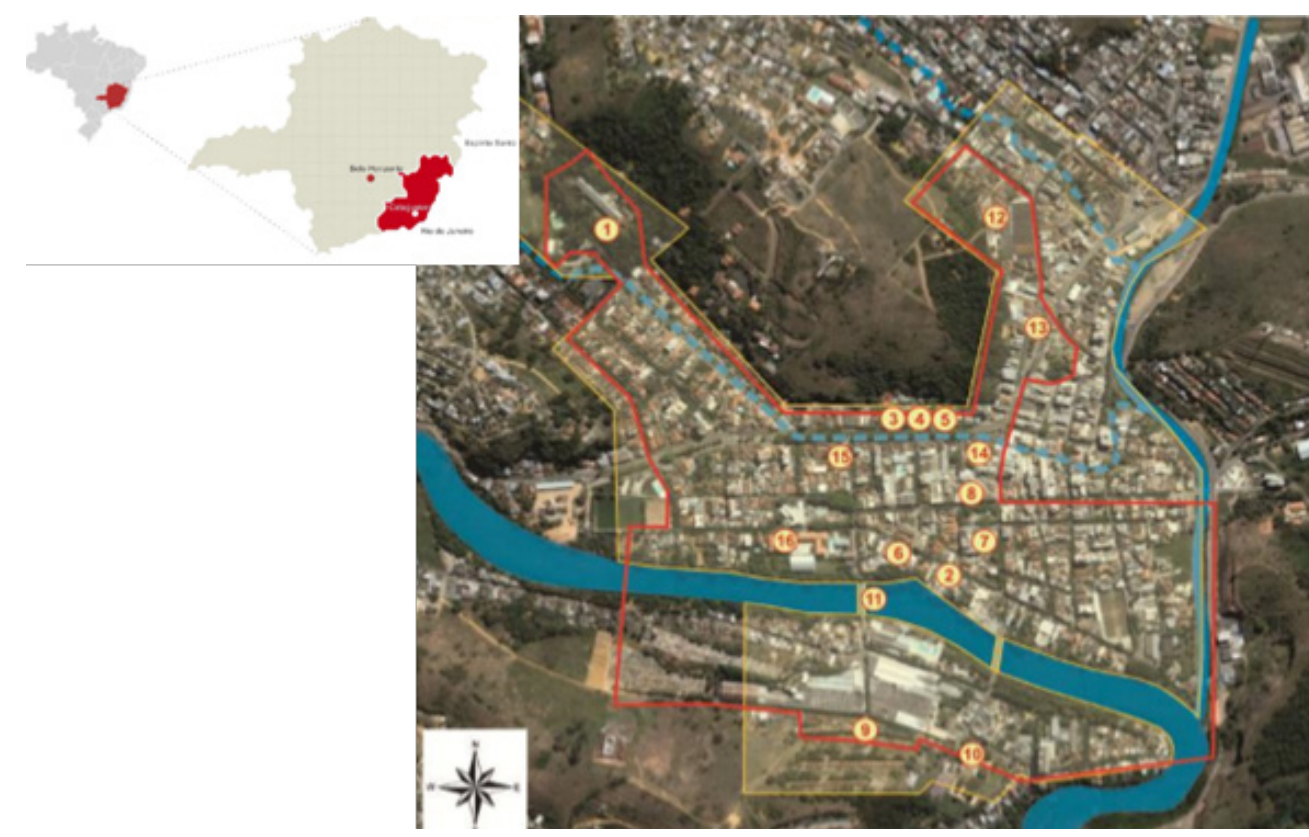

Figura 3: Localização de Cataguases e

seu perímetro de tombamento com as 16 edificações tombadas individualmente pelo Iphan. Fonte: Adaptado de Bahia (2013).

A partir dessas análises in loco e de perspectivas fotográficas da obra (ver Fig. 04), procedimento também indicado por Giovannoni, Cláudio Bahia pôde constatar que não haveria interferência da edificação aos bens significativos do entorno, assim como não causaria danos à paisagem do conjunto, visto que grande parte da área tombada já havia sido verticalizada com alturas superiores à edificação em questão e que, para promover o desbastamento abrindo "janelas" para a paisagem patrimonializada, seria necessário muito mais que a demolição de um pavimento dessa edificação, já que a mesma não apresentava nenhuma "relação de interferência de visibilidade com os elementos polarizadores do Conjunto [...] não se revela na paisagem por causa da verticalização consolidada do entorno destes edifícios" (BAHIA, 2013, p. 24).

Apesar do parecer, como resposta ao Decreto-Lei $n^{\circ} 25 / 37$, em dezembro de 2013, a Entre-Rios Construtora e Incorporadora Ltda. informou ao Iphan, por meio do ofício GAB/IPHAN-MG $n^{\circ} 2.161$ de 2013, que a demolição do quarto pavimento da edificação havia sido executada. Os meses seguintes foram de determinação da multa aplicada, que foi convertida em investimento para a realização de obras em três praças públicas da cidade (Praça Rui Barbosa, Praça Santa Rita e Praça Francisco Inácio Peixoto), fazendo-se valer o decreto-lei em um dos poucos casos do tipo no Brasil. Não nos cabe aqui julgar as escolhas do Iphan ou, ainda, da Construtora; no entanto, é interessante pontuar que a Figura 04 nos revela que o projeto em questão comparece com a mesma altura, mas, no ângulo da foto, se interpõe em aproximação à torre da igreja.

Nos surpreende o fato de que o desbastamento edilício, tão pouco utilizado na prática do Iphan, tenha sido aplicado nessa situação sem uma justificativa clara para além da aplicação do que consta no Decreto-Lei $n^{\circ} 25 / 37$, uma vez que outros imóveis dentro do conjunto tombado já infringiam o que é proposto em tal decreto. Apesar de se constituir como um exemplo de desbastamento edilício parcial - uma vez que apenas um pavimento foi subtraído da paisagem e não o imóvel todo - percebemos que parte da teoria proposta por Giovannoni, de acordo com o que mostra a Figura 04, foi introduzida, em abrir "janelas da paisagem para a cidade" entendida como uma obra de arte. Todavia, o material apresentado por Bahia (2013) não nos dá subsídios 


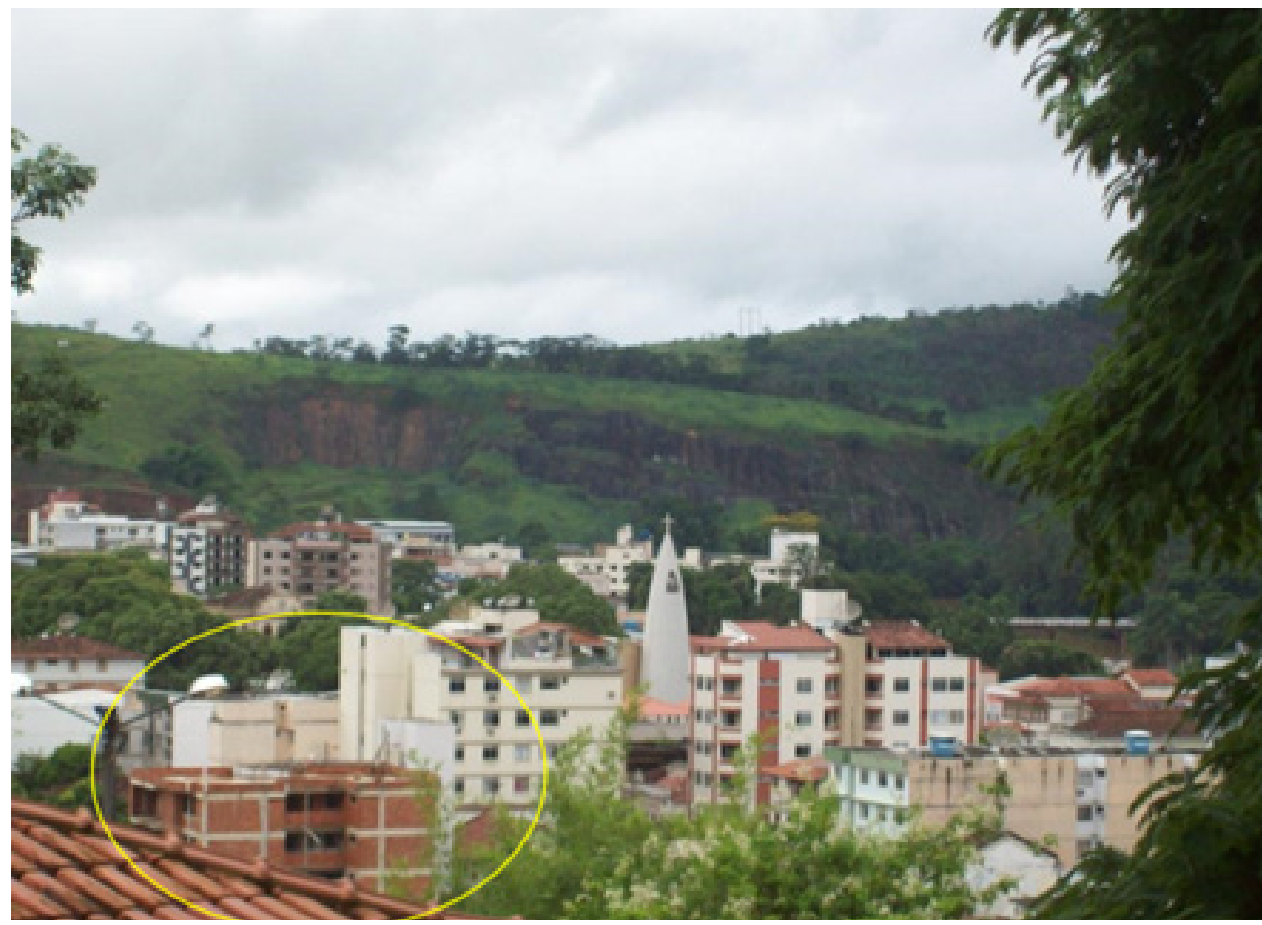

Figura 4: Vista da obra paralisada por ordem do Iphan, com o pavimento que foi demolido e, ao fundo, nota-se a torre da Igreja de Santa Rita de Cássia, em Cataguases, MG. Fonte: BAHIA, 2013.

para tais análises. De toda forma, parcialmente ou não, esse caso ainda é um dos únicos no Brasil em que o instrumento proposto por Giovannoni foi de fato operacionalizado pelo Iphan.

\section{CONSIDERAÇÕES FINAIS}

A narrativa até aqui construída buscou refletir sobre como a apropriação do conceito de paisagem é, desde início do século XX, uma das problemáticas enfrentadas por políticas preservacionistas. O caso italiano merece certa relativização, pois, como vimos, enquanto Giovannoni tecia suas teorias, a própria filosofia da paisagem também estava em estado embrionário. No entanto, as contribuições do engenheiro italiano para o campo da paisagem, mesmo sem a caracterização do conceito, permanecem com grande atualidade. Não apenas a partir dos desafios travados nas duas experiências, como também das possíveis contribuições da obra de Giovannoni para as políticas preservacionistas atuais.
O Iphan insere a condição da paisagem no conceito patrimonial como passível de tombamento ainda no momento de sua criação, em 1937. No entanto, como foi visto, no momento da patrimonialização dos bens imóveis, são outros os conceitos elegidos para a efetiva preservação: "entorno", "visibilidade" e "vizinhança". Tais escolhas adotadas pelo Iphan, todavia, não foram imunes a disputas de jurisprudência de definição dos limites físicos de tais noções. Fato esse que tensionou ainda mais a experiência nacional com a enfrentada na jurisprudência italiana por Giovannoni no início do século XX.

Se a contribuição de Giovannoni para a noção de paisagem é, nos dias de hoje, de fácil aceitação, inclusive por parte da literatura nacional e internacional, foi preciso provar que os termos institucionalizados pelo Iphan seriam também sinônimos de paisagem. Ao estudar os casos aqui analisados de proteção legal, podemos perceber que a noção de "paisagem", por vezes, aparece como uma abordagem menor ou, ainda, como um instrumento para se chegar à "visibilidade", à conservação do "entorno" deseja- 
do. Ou seja, o que o Iphan busca proteger nada mais é do que a própria paisagem, no entanto, percebe-se que ainda permanece uma aparente dificuldade na compreensão ou resistência na aplicação de tal conceito nas políticas preservacionistas nacionais.

A atuação do Iphan atualmente, ao que parece, carece ainda de teorias que tratem a paisagem de forma mais clara e eficiente, não só na efetivação do tombamento, mas, também, na sua posterior gestão. O órgão busca diferentes maneiras de efetuar a salvaguarda de forma mais efetiva e abrangente em suas políticas de preservação, estratégias que nos aproximaram dos dois casos aqui estudados.

O processo da Casa de Chico Mendes pode ser associado à conservação de conjuntos não excepcionais defendida por Giovannoni, apresentando diretrizes na normatização do seu entorno que focalizam uma qualidade paisagística daquele bem, otimizando um futuro que respeita a história e a memória daquela paisagem, como propõe Giovannoni. No entanto, o caso do desbastamento edilício presente no Conjunto urbano de Cataguases nos mostra como o instrumento proposto pelo engenheiro italiano pode ser, sim, um bom aliado às políticas de preservação patrimoniais, mesmo que, nesse caso específico, a utilização da ferramenta se mostre como uma decisão arbitrária, que falha em buscar uma teoria que a justifique.

O cruzamento teórico inicial aqui proposto nos apresenta diferentes possibilidades de atuação para as políticas patrimoniais nacionais, em que a paisagem apresentou potencialidades para vir a ser objeto passível de patrimonialização para além das noções de patrimônio natural. O que a herança crítica de Giovannoni nos revela é que, embora a paisagem possa às vezes não ser elencada como bem a ser preservado em si, há maneiras de essa salvaguarda acontecer ao se recorrer a termos análogos, que buscavam, ainda no século XX, uma atuação mais prática para a preservação do que hoje entendemos por paisagem. Embora a paisagem já possua conceitos bem sedimentados em diversos campos do saber, esse parece ser ainda o desafio que o Iphan busca enfrentar. O que deduzimos é que o conceito de "entorno" já não é mais suficiente para abarcar todas as questões que envolvem o patrimônio cultural como, por exemplo, a questão da memória do local elencada no processo da Casa de Chico Mendes. A paisagem enquanto conceito múltiplo capaz de abranger, inclusive, a memória coletiva local, mostra-se como uma abordagem possível de conter em si diversos aspectos histórico-culturais de uma determinada comunidade. Diante da ineficiência dos instrumentos vigentes como a noção de entorno e visibilidade, assim como a suspensão da Chancela da Paisagem Cultural Brasileira devido às suas divergências conceituais e, consequentemente, sua ineficácia, a prática do Iphan manifesta-se como um caminho a ser traçado.

\section{REFERÊNCIAS BiBLIOGRÁFICAS}

\section{FONTES DOCUMENTAIS}

BAHIA, Cláudio. Parecer técnico de intervenção edilícia no perímetro de tombamento e proteção cultural de Cataguases: Rua Alferes Henrique de Azevedo, 124. Belo Horizonte, 2013

BRASIL. Decreto-Lei $\mathrm{n}^{\circ} 25$ de 30 de novembro de 1937. Organiza a proteção do patrimônio histórico e artístico nacional. Brasília, 1937

ENTRE RIOS CONSTRUTORA E INCORPORADORA LTDA. Ofício GAB/IPHAN-MG nº 2.161, 2013

IPHAN. Autuação ao imóvel à Rua Alferes Henrique de Azevedo, 124. Cataguases, 2012. IPHAN. Portaria ${ }^{\circ} 11$, de 11 de setembro de 1986

IPHAN. Processo de tombamento $\mathrm{n}^{\circ} 1549-\mathrm{T}-07$, Casa de Chico Mendes e seu acervo, Xapuri-AC.

IPHAN. Processo de Tombamento ${ }^{\circ} 1342$ - T - 94, Conjunto Histórico, Arquitetônico e Paisagístico de Cataguases-MG. 


\section{FONTES SECUNDÁRIAS}

ANDRADE, Rodrigo Melo Franco de. Brasil: monumentos históricos e arqueológicos (1952) Reedição comentada. Organização de Maria Beatriz Setubal Rezende da Silva. Rio de Janeiro: IPHAN/DAF/COPEDOC, 2012

ARENA, Antonio. Paesaggio e restauro. In: MOCCIA, Francesco Domenico; SEPE, Marichela (Org.) VIII Giornata di studio INU. Una politica per le citta'Italiana. Italian National Institute of Urban Planning, 2014.

BESSE, Jean-Marc. O gosto do mundo: exercícios de paisagem. Rio de Janeiro: EdUERJ, 2014. p. 26.

BERQUE, Augustin (Dir.). Cinq propositions pour une théorie du paysage. Seyssel: Champ Vallon, 1994.

CABRAL, Renata Campello. A gênese da proteção legal para além do monumento no Brasil: o projeto de José Wanderley de Araújo Pinho e seus diálogos com a legislação estrangeira. Anais do Museu Paulista. São Paulo, Nova Série, vol. 27, 2019, p. 1-41.

CABRAL, Renata Campello. A noção de "ambiente" em Gustavo Giovannoni e as leis de tutela do patrimônio cultural na Itália. Tese (Doutorado) - Programa de Pós-Graduação em Arquitetura e Urbanismo e Área de Concentração em Teoria e História da Arquitetura e do Urbanismo. Instituto de Arquitetura e Urbanismo da Universidade de São Paulo. São Carlos, 2013.

CHOAY, Françoise. A alegoria do patrimônio. São Paulo: Estação Liberdade/Editora UNESP 2001.

COURAJOUD, Michel. A paisagem é o lugar onde o céu e a terra se tocam. In: SERRÃO, Adriana Veríssimo (Coord.). Filosofia da paisagem: uma antologia. Lisboa: Centro de Filosofia da Universidade de Lisboa, 2011. p. 215-225

FREITAS, Pedro Murilo Gonçalves de. O desenho e o reconhecimento do objeto histórico: os princípios metodológicos do projeto de restauro arquitetônico. Tese (doutorado) - Universidade Estadual de Campinas, Faculdade de Engenharia Civil, Arquitetura e Urbanismo, Campinas, SP. 2012. 223 p.

GIOVANNONI, Gustavo. L'ambiente dei monumenti. In: ZUCCONI, Guido (Org.). Da capitello alla città. Milano: Jaca Book, 1999.

GIOVANNONI, Gustavo. O "Desbastamento" de Construções nos Velhos Centros. O Bairro do Renascimento em Roma. In: KUHL, Beatriz (Org). Gustavo Giovannoni: textos escolhidos. Cotia: Ateliê Editorial, 2013a.

GIOVANNONI, Gustavo. Velhas cidades e nova construção urbana. In: KUHL, Beatriz (Org) Gustavo Giovannoni: textos escolhidos. Cotia: Ateliê Editorial, 2013b.

MOTTA, Lia; THOMPSON, Ana Lucia. Entorno de bens tombados. Rio de Janeiro: IPHAN/ DAF/Copedoc, 2010.

PANE, Andrea. A atualidade de Gustavo Giovannoni. in: KUHL, Beatriz (Org.). Gustavo Giovannoni: Textos escolhidos. Cotia: Ateliê Editorial, 2013.

RAPALO, Maria Chiara. Alle origini della conservazione del paesaggio in Belgio: il

contributo original di Louis Van der Swaelmen. Tesi di Dottorato in architettura XXIX ciclo. Università degli Studi di Napoli Federico II, Napoli, 2017.

SANT'ANNA, Márcia. Da cidade monumento à cidade documento: A trajetória da norma de preservação das áreas urbanas no Brasil, 1937-1990. Dissertação (mestrado), Universidade Federal da Bahia, Salvador, 1995.

SIMMEL, Georg. A filosofia da paisagem (1913). Coleção Textos Clássicos de Filosofia. Covilhã: Universidade da Beira Interior, 2009.

SITTE, Camilo. A construção de cidades segundo os seus princípios artísticos. São Paulo: Atlas, 1992

VERAS, Lúcia Maria de Siqueira Cavalcanti. Paisagem-postal: a imagem e a palavra na compreensão de um Recife urbano. Tese (Doutorado em Desenvolvimento Urbano) Universidade Federal de Pernambuco, Recife. 2014.

ZANIRATO, Silvia Helena. Paisagem cultural e espírito do lugar como patrimônio: em busca de um pacto social de ordenamento territorial. Revista CPC, [S. I.] v. 15, n. 29, p. 8-35, 2020. DOI: 10.11606/issn.1980-4466.v15i29p8-35. Disponível em: https://www.revistas.usp.br/cpc/ article/view/161594. Acesso em: 9 de março de 2021.

ZUCCONI, Guido (Org.). Dal capitello alla città. Milano: Jaca Book, 1999. 
Hugo Stefano Monteiro Dantas

Universidade Federal de Pernambuco. Programa de Pós Graduação em Desenvolvimento Urbano (MDU-UFPE), Laboratório de Urbanismo e Patrimônio Cultural (LUP)

Avenida da Arquitetura, s/n, Universidade Federal de Pernambuco, Cidade Universitária, CEP 50740-550, Recife-PE-Brasil

https://orcid.org/0000-0002-8714-7894

hugostmd@gmail.com

Pedro Augusto Queiroz de Souza

Universidade Federal de Pernambuco. Programa de Pós Graduação em Desenvolvimento Urbano (MDU-UFPE), Laboratório da Paisagem.

Avenida da Arquitetura, s/n, Universidade Federal de Pernambuco, Cidade Universitária, CEP 50740-550, Recife-PE-Brasil

https://orcid.org/0000-0002-1299-1070

pqueiroz.arq@gmail.com

Mariana Silva Rossin

Universidade Federal de Pernambuco. Programa em Desenvolvimento Urbano (MDU - UFPE). Laboratório da Paisagem.

Avenida da Arquitetura, s/n, Universidade Federal de Pernambuco, Cidade Universitária, CEP 50740-550, Recife-PE-Brasil

https://orcid.org/0000-0003-1372-8124

marianarossin.arq@hotmail.com

Thamires Augusto de Barros Chaves

Universidade Federal de Pernambuco. Programa de Pós Graduação em Desenvolvimento Urbano (MDU-UFPE)

Avenida da Arquitetura, s/n, Universidade Federal de Pernambuco, Cidade Universitária, CEP 50740-550, Recife-PE-Brasil

https://orcid.org/0000-0002-9275-8040

thamires_chaves@hotmail.com
Ana Rita Sá Carneiro

Universidade Federal de Pernambuco. Departamento de Arquitetura e Urbanismo (UFPE). Laboratório de Paisagem.

Avenida da Arquitetura, s/n, Universidade Federal de Pernambuco, Cidade Universitária, CEP 50740-550, Recife-PE-Brasi

https://orcid.org/0000-0002-2750-5354

anaritacarneiro@hotmail.com
Nota do editor

Data de Submissão: 21/10/2020

Aprovação: 10/03/2021

Revisão: RMO 